\title{
ATIVOS INTANGÍVEIS, GRAU DE INOVAÇÃO E 0 DESEMPENHO DAS EMPRESAS BRASILEIRAS DE GRUPOS SETORIAIS INOVATIVOS ${ }^{1}$ \\ INTANGIBLE ASSETS, DEGREE OF INNOVATION, AND THE BUSINESS PERFORMANCE OF BRAZILIAN COMPANIES IN THE INNOVATIVE \\ SECTORIAL GROUPS \\ KLÉBER FORMIGA MIRANDA² | ALESSANDRA CARVALHO DEVASCONCELOS ${ }^{3}$ JOSÉ CARLOS LÁZARO DA SILVA-FILHO ${ }^{4} \mid$ JOSÉ GLAUBER CAVALCANTE DOS SANTOS 5 ANNA BEATRIZ GRANGEIRO RIBEIRO MAIA ${ }^{6}$
}

\section{RESUMO}

Nos últimos anos, a variedade de mudanças inerentes ao ambiente organizacional tem sido objeto de discussão nos meios corporativo e acadêmico, sendo identificada a inovação como importante elemento de determinação para o melhor desempenho empresarial. Esse cenário induz à questão de que empresas com forte caráter inovador teriam intensivos investimentos em intangíveis e apresentariam vantagens competitivas capazes de influenciar a geração de valor para a empresa - enfoque adotado como pressuposto teórico do estudo. A pesquisa analisa a relação entre as variáveis ativos intangíveis e grau de inovação e o desempenho das empresas listadas na BM\&FBovespa, participantes dos setores mais inovadores do Brasil, segundo classificação do Índice Brasil de Inovação (IBI). Trata-se de pesquisa descritiva, de natureza quantitativa, reunindo uma amostra de 174 empresas, compreendendo os anos de 2008 e 2009. Para tanto, utilizou-se como proxies: para os ativos intangíveis, os valores contábeis desses ativos divulgados nas demonstrações financeiras das empresas e para o grau de inovação, considerou-se o grupo de intensidade tecnológica que se enquadrasse à empresa, conforme a classificação setorial do IBI. O desempenho empresarial foi mensurado a partir do valor de mercado e o retorno do patrimônio líquido (ROE) das empresas disponível na base de dados do Economática ${ }^{\circledR}$. Os resultados indicam que os investimentos em ativos intangíveis têm relação positiva com o valor de mercado das empresas pesquisadas, mas não se confirmou o mesmo contexto com o ROE. Quanto ao grau de inovação, os resultados indicaram haver relação positiva entre o ROE e os investimentos em intangíveis das empresas componentes do grupo 3 do IBI e negativa com as do grupo 2. Nenhuma evidência estatisticamente significante pode ser inferida sobre a relação entre o grau de inovação da empresa e a maximização do seu valor de mercado.

Palavras-chave: Ativos intangíveis. Inovação. Valor da empresa. Retorno do Patrimônio Líquido (ROE).

\section{ABSTRACT}

In the last years, a variety of changes inherent to the organizational environment has been the subject of discussion in the academic and corporate community, identifying innovation as an important determination factor for the best business performance. This scenario induces to the issue that companies with strong innovative character would have intensive investments in intangible and would show competitive advantages that can influence the creation of value for the company - adopted focus as theoretical assumption of the study. The research examines the relationship between intangible assets variables and degree of innovation and the performance of companies listed on the BM\&FBovespa, participants of the most innovative sectors of Brazil, according to the Brazil Innovation Index (IBI) classification. It is a descriptive research, with quantitative nature, gathering a sample of 174 companies, comprising the years 2008 and 2009. For this, it was used as proxies: for intangible assets, the accounting values of these assets disclosed in the financial statements of companies and for the degree of innovation, it was considered the group of technological intensity that would fit to the company, according to the sectorial classification of the IBI. The business performance was measured from the market value of the companies and the Return On Equity (ROE) available in the database of Economática ${ }^{\circledR}$. The results indicate that investments in intangible assets have positive relationship with the market value of the surveyed companies, but didn't confirm the same context with the ROE. Relative to the degree of innovation, the results showed a positive relationship between ROE and investments in intangible of the companies that are part of group 3 in the IBI and negative with the company group 2 . There is no statistical evidence that can be inferred about the relationship between the degree of innovation of the company and the maximization of its market value.

Keywords: Intangible assets. Innovation. Company value. Return on Equity (ROE). Brazilian Innovation Index (IBI). 


\section{INTRODUÇÃO}

A inovação pode ser considerada como uma invenção que venceu os vários riscos associados, tanto tecnológicos quanto de mercado, e chegou ao mercado, gerando valor para os stakeholders envolvidos (GARCIA; CALANTONE, 2002).

Santos, Basso e Kimura (2010) comentam que a inovação tem recebido uma atenção crescente, desde a segunda década do último século, sendo que os estudos empíricos que tratam as relações entre a inovação e o desempenho empresarial são cada vez mais frequentes, muitos dos quais apresentaram resultados divergentes.

Conforme a terceira edição do Manual de Oslo da Organisation for Economic Co-operation and Development (OECD, 2005), a inovação envolve investimentos relevantes que incluem a aquisição de ativos intangíveis que podem render retornos potenciais no futuro.

Nesta mesma linha, em pesquisa realizada pelo Instituto de Pesquisa Econômica Aplicada (IPEA), Tironi e Cruz (2008) destacam o papel dos recursos intangíveis (conhecimento e capacidade de aprendizagem) para a inovação das empresas na era da economia do conhecimento e consideram como argumento central de seu trabalho que um maior grau de novidade requer maior proporção de absorção de intangíveis na atividade inovadora.

Por sua vez, Teh, Kayo e Kimura (2008, p. 88) afirmam que "a inovação é um importante ativo intangível. Ele gera vantagens competitivas sustentáveis que permitem erguer barreiras contra algumas das ameaças competitivas", o que reforça a relação entre os temas ativos intangíveis e inovação, associando-os à sobrevivência das empresas no contexto atual.

Buscando retratar a nova estrutura patrimonial das empresas marcada pela representatividade dos ativos intangíveis, no contexto contábil, estabeleceu-se o registro obrigatório dos ativos intangíveis no Balanço Patrimonial das empresas a partir da edição da Lei no 11.638/2007, que tornou compulsória a introdução do Intangível no Ativo Não Circulante. Em seguida, o Pronunciamento Técnico CPC 04 (2008), alterado em 2010 pelo CPC 04 (R1), com base no International Accounting Standard (IAS) 38, estabeleceu critérios de contabiliza- ção relativos ao reconhecimento e mensuração dos ativos intangíveis das demonstrações financeiras das empresas brasileiras.

Ao considerar a necessidade de ativos intangíveis para a inovação, o pressuposto teórico da presente pesquisa considera que empresas com forte caráter inovador teriam intensivos investimentos em ativos intangíveis e, ao gerarem vantagens competitivas, esses investimentos influenciariam positivamente no valor de mercado destas empresas, representando o reconhecimento de perspectiva de retornos futuros e na taxa de retorno do patrimônio líquido (capital próprio), caracterizando o bônus pelo investimento realizado em intangíveis.

Do exposto, este estudo procura responder ao seguinte questionamento: os investimentos em ativos intangíveis e o grau de inovação de empresas participantes dos setores mais inovadores do Brasil possuem relação positiva com seu desempenho?

De acordo com essa problemática e com as considerações da literatura, segundo as quais a inovação envolve investimentos em ativos intangíveis que, em consequência, gera resultados positivos, o presente estudo levanta as seguintes hipóteses:

$H_{1}$ : há uma relação positiva entre investimentos em ativos intangíveis e o desempenho das empresas de grupos setoriais inovativos. Para análise dessa hipótese serão validadas as seguintes sub-hipóteses:

$\mathrm{H}_{1.1}$ : há uma relação positiva entre investimentos em ativos intangíveis e o valor de mercado das empresas de grupos setoriais inovativos.

$\mathrm{H}_{1.2}$ : há uma relação positiva entre investimentos em ativos intangíveis e o retorno do patrimônio líquido das empresas de grupos setoriais inovativos; e

$H_{2}$ : o grau de inovação das empresas de grupos setoriais inovativos relaciona-se positivamente com seu desempenho. Da mesma forma, essa hipótese também se subdivide em duas sub-hipóteses:

$\mathrm{H}_{2.1}$ : o grau de inovação das empresas de grupos setoriais inovativos relaciona-se positivamente com seu valor de mercado.

$\mathrm{H}_{2.2}$ : o grau de inovação das empresas de grupos setoriais inovativos relaciona-se positivamente com seu retorno sobre o patrimônio líquido.

As análises propostas fundamentam-se na premissa de que investimentos realizados pelas em-

\footnotetext{
${ }^{1}$ Data de submissão: 09/01/2013. Data de aceite: 01/08/2013. Data de publicação: 21/02/2014.

${ }^{2}$ Mestre em Administração e Controladoria pela Universidade Federal do Ceará (UFC) e Professor Assistente da Universidade Federal Rural do Semi-Árido (UFERSA). E-mail: mirandakf@ufersa.edu.br.

${ }^{3}$ Doutora em Engenharia de Produção pela Universidade Federal de Santa Catarina (UFSC) e Professora Adjunta da Universidade Federal do Ceará (UFC). E-mail: alegallon@terra.com.br..

${ }^{4}$ Doutor em Planejamento Ambiental pela Technische Universität-Berlin (Alemanha) e Professor Adjunto da Universidade Federal do Ceará (UFC). E-mail: lazaro.ufc@gmail.com.

${ }^{5}$ Mestrando em Administração e Controladoria pela Universidade Federal do Ceará (UFC). E-mail: jglauber_cont@hotmail.com.

${ }^{6}$ Mestranda em Administração e Controladoria pela Universidade Federal do Ceará (UFC). E-mail: deluxedama@ hotmail.com.
} 


\section{ALESSANDRA CARVALHO DE VASCONCELOS, JOSÉ CARLOS LÁZARO DA SILVA-FILHO, \\ JOSÉ GLAUBER CAVALCANTE DOS SANTOS, ANNA BEATRIZ GRANGEIRO RIBEIRO MAIA}

presas em ativos intangíveis requerem a identificação de inovações pelo mercado para ter reflexo no seu valor de mercado e, consequentemente, na taxa de retorno aos acionistas, mesmo porque o êxito da inovação só deve ser confirmado se o valor criado com ela for superior às despesas e custos incorridos no seu desenvolvimento, conforme considerações levantadas por Carvalho (2009).

Assim, o objetivo geral do presente estudo consiste em analisar a relação entre as variáveis ativos intangíveis e grau de inovação e o desempenho das empresas listadas na BM\&FBovespa, participantes dos setores mais inovadores do Brasil, segundo classificação do Índice Brasil de Inovação (IBI). Essas empresas foram criteriosamente selecionadas, com base no fato de que, devido ao seu forte caráter inovador, promoveriam intensivos investimentos em intangíveis, os quais, por consequência, teriam ampla evidenciação contábil.

Essa pesquisa adota a denominação constitutiva de desempenho empresarial a valoração da empresa pelo mercado, representa pelo valor de mercado, e o retorno do patrimônio líquido que demonstra a remuneração do capital do acionista pelos investimentos realizados nas empresas.

Partindo da taxonomia para inovação de Pavitt (1984), que considera diferença do uso da inovação entre os setores industriais, a classificação setorial de inovação do IBI pressupõe a identificação de similaridades de comportamento tecnológico entre as empresas para qualificá-las como pertencentes a um mesmo grupo de intensidade tecnológica, a saber: Grupo 1: setores de alta tecnologia; Grupo 2: setores de média-alta intensidade tecnológica; Grupo 3: setores de média-baixa intensidade tecnológica; e Grupo 4: setores de baixa intensidade tecnológica.

$\mathrm{O}|\mathrm{B}|$ tem como matriz conceitual e metodológica as diretrizes das pesquisas de inovação que seguem os conceitos do Manual de Oslo (OECD, 2005), de maneira que os indicadores de inovação considerados na composição do índice estão ancorados em uma abordagem suficientemente ampla e abrangente para uma aproximação do que seria a capacidade efetiva de inovação das empresas. Cabe destacar que o ranking setorial construído pela metodologia do IBI a partir dos dados da PINTEC (2005), foi utilizado nos trabalhos de Furtado e Quadros (2006), Inácio Jr. e Quadros (2006), Furtado et al. (2007), Furtado, Quadros e Domingues (2007), Quadros e Furtado (2007), Righetti e Pallone (2007) e aplicado nos estudos de Oyadomari et al. (2010), Cardoso et al. (2012), Santos et al. (2012), dentre outros.

O presente estudo justifica-se pela aplicabilidade de seus resultados, cujas conclusões podem apresentar parâmetros e contribuir para o processo de tomada de decisões empresariais quanto à qualificação da gestão de seus recursos, hodiernamente voltados a investimentos em ativos intangíveis, dada a necessidade emergente de inovar e adquirir novas tecnologias por meio de fusões e aquisições de empresas. Torna-se oportuno salientar que a cada dia as discussões sobre os ativos intangíveis no contexto da evidenciação contábil ganham mais destaque nos âmbitos acadêmico e corporativo, principalmente devido ao cenário de consolidação dos padrões internacionais de contabilidade no Brasil, apoiado nas Leis no $11.638 / 2007$ e no 11.941/2009 e também nos documentos emitidos pelo Comitê de Pronunciamentos Contábeis (CPC).

O artigo está organizado em cinco seções, além desta introdução, é apresentado o arcabouço teórico que serve como fundamentação para a pesquisa. Na terceira seção aborda-se a metodologia que norteou a condução do estudo. Na quarta seção são debatidos os resultados encontrados. Por fim, as considerações a que o estudo permitiu chegar.

\section{REVISÃO TEÓRICA}

A revisão teórica abordará os temas inovação e seus indicadores. Apresentará alguns estudos empíricos anteriores sobre inovação e medidas de desempenho empresarial, com o objetivo de apoiar a discussão sobre como essas temáticas se relacionam.

\section{Inovação e seus indicadores}

Desde 1962, com a edição do Manual Frascati que deu origem a publicações posteriores da OCDE (como o Manual de Oslo), o tema inovação vem sendo conduzido por meio de orientações e padronização de conceitos, metodologias e construção de estatísticas e indicadores de P\&D de países industrializados (OCDE, 2005). Para a OCDE (2005), os dados sobre inovação podem ter usos variados, porém, os focos principais são a possibilidade de melhor compreensão da relação entre inovação e crescimento econômico e a disponibilização de indicadores para confrontar o desempenho nacional com as práticas existentes.

Seguindo a ideia inicial de Schumpeter (1988), diversos autores, como Zaltman, Duncan e Holbek (1973) entendem a definição de inovação como uma ideia, uma prática ou um artefato material percebido como novo, relevante e único, adotado em determinado processo, área ou por toda a organização. Por sua vez, a terceira edição do Manual de Oslo (OECD, 2005, p. 55) apresenta a seguinte definição de inovação: "é a implementação de um produto (bem ou serviço) novo ou significativa- 
mente melhorado, ou um processo, ou um novo método de marketing, ou um novo método organizacional nas práticas de negócios, na organização do local de trabalho ou nas relações externas".

Apesar de a literatura existente apresentar diversas tipologias de inovação tanto em relação ao grau (GARCIA; CALANTONE, 2002; CARVALHO, 2009) quanto em relação ao objeto da mesma (DAFT, 1978; KIMBERLY; EVANISKO, 1981; DAMANPOUR, 1987), neste trabalho é utilizada a tipologia de inovação apresentada pelo Manual de Oslo (OECD, 2005) que diferencia quatro tipos de inovação quanto ao objeto: (1) de produto e/ou serviço, (2) de processo, (3) de marketing e (4) organizacional.

No caso específico desta pesquisa, são investigados os dois primeiros tipos de inovação. É considerada como inovação de produto e/ou serviço a(s) mudança(s) significativa(s) nas potencialidades de produtos e serviços, que incluem bens e serviços totalmente novos ou aperfeiçoamentos importantes para produtos existentes; e como inovação de processo a(s) mudança(s) significativa(s) nos métodos de produção e de distribuição, ambos demandantes de intensidade de $\mathrm{P} \& \mathrm{D}$ (indicador central do grau de inovação, segundo o IBI).

Assim como não há consenso na literatura quanto aos tipos de inovação, no que se refere aos indicadores e índices de inovação, estes também apresentam diferenças e similaridades. Archibugi e Coco (2005) enfatizam que medir capacidades tecnológicas é mais complicado que mensurar outros fenômenos, como os econômicos e sociais, uma vez que a natureza da tecnologia, com seus aspectos e componentes heterogêneos torna difícil a agregação em um único índice significante que permita prover informação das capacidades tecnológicas de um país como um todo.
No Brasil, o Instituto Brasileiro de Geografia e Estatística (IBGE) com apoio da Financiadora de Estudos e Projetos (FINEP) desenvolve a Pesquisa de Inovação Tecnológica (PINTEC). O objetivo do estudo é pesquisar, através de recomendações internacionais, as empresas brasileiras de setores industriais e de serviços de alta tecnologia e atualizar dados de edições anteriores (IBGE, 2006).

A pesquisa, que teve sua quarta edição baseada no triênio 2006-2008 (IBGE, 2010) e sua primeira edição em 2000 (1998-2000) analisa e aponta indicadores de inovação, bem como apresenta classificação das atividades de acordo com o grau inovativo das empresas. Dentre os indicadores apontados pelo Manual de Oslo e pela PINTEC, podem-se citar: a) recursos destinados a P\&D; b) estatística de patentes; c) estatística de publicações científicas; d) adoção de tecnologias da informação e da comunicação; e) gerenciamento do conhecimento e; f) investimentos intangíveis como marketing não-rotineiro, treinamento, software e despesas correntes em P\&D.

Em 2005 teve início o projeto IBI - Índice Brasil de Inovação - utilizado no presente estudo - com o objetivo de medir a capacidade inovativa das empresas para construção de uma classificação de empresas brasileiras inovadoras (FURTADO et al., 2007). O IBI é composto por um primeiro nível de macro-indicadores (Indicador Agregado de Esforço - IAE e Indicador Agregado de Resultado - IAR), divididos em um segundo nível de quatro mesoindicadores (IAI - Indicador de Atividade Inovadora, IRH - Indicador de Recursos Humanos, IRV - Indicador de Receitas de Vendas com novos produtos, e IPT - Indicador de Patentes), que, por sua vez, é subdividido em um terceiro nível de microindicadores, num total de 16 micro-indicadores, conforme apresenta o Quadro 1.

Quadro 1: Macro e microindicadores utilizados pelo IBI

\begin{tabular}{|c|c|}
\hline $\begin{array}{c}\text { Macroindicadores utilizados } \\
\text { pelo IBI }\end{array}$ & Microindicadores utilizados pelo IBI \\
\hline $\begin{array}{l}\text { Indicador Agregado de } \\
\text { Esforço - IAE }\end{array}$ & $\begin{array}{l}\text { Dispêndios com P\&D Interna, dispêndios com P\&D Externa, dispêndios com Outros } \\
\text { Conhecimentos Externos, dispêndios com Software, dispêndios com Máquinas e Equi- } \\
\text { pamentos, dispêndios com Treinamento, dispêndios com Lançamento de Produto, dis- } \\
\text { pêndios com Projeto Industrial, total de Graduados ocupados em P\&D, total de Mestres } \\
\text { ocupados em P\&D e total de Doutores ocupados em P\&D. }\end{array}$ \\
\hline $\begin{array}{l}\text { Indicador Agregado de } \\
\text { Resultado - IAR }\end{array}$ & $\begin{array}{l}\text { Receita total de vendas com produtos novos para a empresa, receita total de vendas com } \\
\text { produtos novos para o mercado nacional, receita total de vendas com produtos novos } \\
\text { para o mercado mundial, total de patentes/registro de programas de computador deposi- } \\
\text { tados e total de patentes/registro de programas de computador concedidos. }\end{array}$ \\
\hline
\end{tabular}

Fonte: Adaptado de Furtado et al. (2007). 


\section{ALESSANDRA CARVALHO DE VASCONCELOS, JOSÉ CARLOS LÁZARO DA SILVA-FILHO, \\ JOSÉ GLAUBER CAVALCANTE DOS SANTOS, ANNA BEATRIZ GRANGEIRO RIBEIRO MAIA}

Por meio dos indicadores apresentados no Quadro 1, o IBI classifica as atividades econômicas das empresas em quatro grupos, conforme a intensidade de P\&D. No Grupo 1 ( $1^{\circ}$ quartil) encontram-se as atividades potencialmente inovadoras e no Grupo 4 ( $4^{\circ}$ quartil) são listadas as atividades com menor potencial de inovação. Para tanto, neste estudo, a mensuração do grau de inovação das empresas considera a classificação setorial do IBI.

Apresenta-se, a seguir, a revisão de literatura que evidenciou algumas pesquisas voltadas, direta ou indiretamente, aos ativos intangíveis e à inovação sob a perspectiva das medidas de desempenho empresarial, dentre as quais se destacam as medidas de valoração das empresas pelo mercado.

\section{Estudos empíricos anteriores sobre inovação e medidas de desempenho empresarial}

Nos últimos anos a indagação acerca da relação entre os temas ativos intangíveis, inovação e desempenho empresarial gerou uma série de pesquisas nacionais (KAYO et al., 2006; PEREZ; FAMÁ, 2006; TEH; KAYO; KIMURA, 2008; TIRONI; CRUZ, 2008; SANTOS; CRISÓSTOMO, 2009; BRITO, E.; BRITO, L.; MORGANTI, 2009; BARROS JUNIOR et al., 2010; BASSO; KIMURA, 2010; KUSTHER et al., 2010; QUEIROZ, 2010; RITTA; ENSSLIN, 2010; STOECKICHT; SOARES, 2010; SQUENA; PASUCH， 2010; ALBUQUERQUE JUNIOR; LIMA; LÁZARO, 2011; ARANTES; FURQUIM, 2011; BRASIL; NOGUEIRA; FORTE, 2011; NISIYAMA; OYADOMARI, 2012; BARBOSA; CINTRA, 2012) e internacionais (ROGERS, 1998; BLUNDELL; GRIFFITHS; VAN REENENL, 1999; LEV, 2001; DARROCH; MCNAUGHTON, 2002; JEFFERSON et al., 2003; EDVINSSON et al., 2004; NARVEKAR; KARUNA, 2006MUDAMBI, 2008; KOELLINGERA, 2008; SORESCU; SPANJOL, 2008; DAMANPOUR; WALKER; AVELLANEDA, 2009; LEE; CHEN, 2009; LICHTENTHALER, 2009; KIRNER; KINKEL; JAEGER, 2009; ROSENBUSCHA; BRINCKMANNB; BAUSCH， 2011; GARCÍA-MORALES; JIMÉNEZ-BARRIONUEVO; GUTIÉRREZ-GUTIÉRREZ, 2012), muitas das quais apresentaram resultados contraditórios e, algumas vezes, inconsistentes.

Os investimentos realizados em iniciativas para inovação geram perspectivas de retorno futuro, cujos valores investidos acabam por incorporar o componente patrimonial das empresas denominado de ativos intangíveis (base de investigação deste estudo).

Importante ressaltar que conforme o normativo contábil brasileiro Pronunciamento Técnico
CPC 04, emitido pelo Comitê de Pronunciamentos Contábeis (CPC) em 2008, nem todos os dispêndios nessas iniciativas podem ser considerados como ativos intangíveis (CPC 04, 2008). No Brasil, as alterações recentes na legislação contábil têm como objetivo a sua convergência para o padrão internacional (IFRS). De acordo com o Pronunciamento Técnico CPC 04 (2008), alterado pelo CPC 04 (R1) em 2010, um ativo intangível satisfaz o critério de ativo quando for separável, resultar de direitos contratuais e for controlado pela entidade.

Lev (2001) indica que o interesse em ativos intangíveis se deve à competição e ao desenvolvimento de tecnologia da informação, elevando os ativos intangíveis ao nível de maior direcionador de valor das empresas. Assim, não seria inadequado, portanto, relacionar a inovação aos ativos intangíveis, visto que os esforços para inovar são caracterizados como tais ativos, cabendo reforçar, conforme Carvalho (2009), que a inovação é um processo que se inicia pela percepção de um novo mercado, distinguindo-se da invenção, que só se torna inovação quando se estabelece no mercado, e seu impacto econômico-financeiro está ligado intimamente à sua difusão.

Logo, verifica-se que a inovação sugere perspectiva de resultados futuros, característica essencial para um ativo. Usando dados sobre mais de 20.000 novos produtos da indústria de bens de consumo embalados, Sorescu e Spanjol (2008) constataram que o avanço da inovação está associado ao aumento no valor das empresas analisadas. O estudo revelou ainda que o avanço da inovação também está associado ao aumento do risco de inovar das empresas, mas que este risco mais elevado é compensado por retornos acima do normal. Os resultados de Nisiyama e Oyadomari (2012, p. 194) corroboram com os de Sorescu e Spanjol (2008) por demonstrarem que "as transformações tecnológicas ou inovações em qualquer parte da cadeia de valores são fundamentais para a competitividade da empresa".

Diferentes teorias, como as teorias de marketing e estratégicas, também revelam que a inovação organizacional é essencial para um melhor desempenho e para a consequente criação de valor da empresa (GARCÍA-MORALES; JIMÉNEZ-BARRIONUEVO; GUTIÉRREZ-GUTIÉRREZ, 2012), e dentro desta abordagem os recursos intangíveis, pela sua própria natureza, destacam-se substancialmente.

Nesse contexto, a presente pesquisa investiga a existência de relação entre as variáveis ativos intangíveis (proxy para inovação) e grau de inovação e o valor de mercado de empresas participantes dos setores mais inovadores do Brasil. Cabe ressal- 
tar que as variáveis explicativas utilizadas nos testes estatísticos que serão realizados na presente pesquisa foram fundamentadas nos estudos seminais de Durand (1952), Spence (1973) e Jensen e Meckling (1976).

\section{PROCEDIMENTOS METODOLÓGICOS}

Esta pesquisa descritiva, de natureza quantitativa, busca investigar, conforme explanação teórica e empírica, a relação entre as variáveis "ativos intangíveis" e "grau de inovação" e o "valor de mercado" de empresas que possuem atividades potencialmente inovadoras, segundo o IBI, pressupondo que investimentos em intangíveis revelam vantagem competitiva para as empresas.

Para responder à questão de pesquisa, a seleção das empresas que compuseram a sua amostra se deu a partir da população de 174 empresas listadas na BM\&FBovespa, cujas atividades econômicas se enquadram naquelas previstas pela classificação setorial de inovação do IBI. A formação desta classificação setorial do IBI pressupõe a identificação de similaridades de comportamento tecnológico entre as empresas para qualificá-las como pertencentes a um mesmo grupo de intensidade tecnológica, a saber: Grupo 1: alta tecnologia, Grupo 2: média-alta intensidade tecnológica, Grupo 3: mé- dia-baixa intensidade tecnológica e Grupo 4: baixa intensidade tecnológica.

Para tanto, foram considerados: os investimentos em ativos intangíveis com evidenciação nas demonstrações financeiras divulgadas pelas empresas no sítio eletrônica da BM\&FBovespa, o grau de inovação de cada empresa mensurado a partir da respectiva classificação setorial de inovação do $|\mathrm{B}|$ e as variáveis valor de mercado e Retorno do Patrimônio Líquido (ROE) das empresas disponível na base de dados do Economática ${ }^{\circledR}$ (DURAND, 1952; SPENCE, 1973; JENSEN; MECKLING, 1976). Os investimentos em ativos intangíveis foram analisados considerando o total investido em cada ano analisado, pois dados detalhados sobre a composição dos investimentos são, normalmente, omitidos por declararem algumas estratégias empresariais. Contudo, propõe-se que esses investimentos se voltem aos propostos no Quadro 1 com predominância de origem interna.

Os dados para análise compreenderam os anos de 2008 e 2009. As empresas que não possuíam informações contábeis disponíveis no banco de dados da Economática ${ }^{\circledR}$ nesse período foram excluídas da amostra, resultando no total uma amostra de 100 empresas. A Tabela 1 apresenta a distribuição de empresas da amostra por grupo setorial de inovação, conforme o IBI.

Tabela 1: Distribuição de empresas da amostra por atividades econômicas

\begin{tabular}{|c|c|c|c|c|c|}
\hline \multirow{2}{*}{$\begin{array}{l}\text { Classificação Nacional de Atividades Econômicas (CNAE) } \\
\text { Atividades de informática e serviços relacionados }\end{array}$} & \multirow{4}{*}{$\begin{array}{c}\text { Grupo } \\
\mid \mathrm{IB|}\end{array}$} & \multicolumn{2}{|c|}{$\begin{array}{c}\text { № de empresas } \\
\text { por Setor }\end{array}$} & \multicolumn{2}{|c|}{$\begin{array}{c}\text { № de empresas } \\
\text { por Grupo }\end{array}$} \\
\hline & & 4 & $4 \%$ & & \\
\hline Máquinas para escritório e equipamentos de informática & & 3 & $3 \%$ & 14 & $14 \%$ \\
\hline Veículos, reboques e carrocerias & & 7 & $7 \%$ & & \\
\hline Fabricação de máquinas e equipamentos & \multirow{4}{*}{$\begin{array}{c}\text { Grupo } \\
2\end{array}$} & 10 & $10 \%$ & \multirow{4}{*}{32} & \multirow{4}{*}{$32 \%$} \\
\hline Fabricação de produtos químicos & & 10 & $10 \%$ & & \\
\hline Refino de petróleo e álcool & & 4 & $4 \%$ & & \\
\hline Telecomunicações & & 8 & $8 \%$ & & \\
\hline Confecção de artigos do vestuário e acessórios & \multirow{6}{*}{$\begin{array}{c}\text { Grupo } \\
3\end{array}$} & 3 & $3 \%$ & \multirow{6}{*}{20} & \multirow{6}{*}{$20 \%$} \\
\hline Couros, calçados e fabricação de artefatos de couro & & 3 & $3 \%$ & & \\
\hline Fabricação de celulose, papel e produtos de papel & & 3 & $3 \%$ & & \\
\hline Fabricação de produtos de minerais não metálicos & & 3 & $3 \%$ & & \\
\hline Fabricação de produtos de fumo & & 1 & $1 \%$ & & \\
\hline Fabricação de produtos têxteis & & 7 & $7 \%$ & & \\
\hline Edição, impressão e reprodução de gravações & \multirow{6}{*}{$\underset{4}{\text { Grupo }}$} & 1 & $1 \%$ & \multirow{6}{*}{34} & \multirow{6}{*}{$34 \%$} \\
\hline Fabricação de produtos alimentícios e bebidas & & 17 & $17 \%$ & & \\
\hline Fabricação de produtos de madeira & & 2 & $2 \%$ & & \\
\hline Fabricação de produtos de metal & & 1 & $1 \%$ & & \\
\hline Indústrias extrativas & & 2 & $2 \%$ & & \\
\hline Metalúrgica básica & & 11 & $11 \%$ & & \\
\hline
\end{tabular}

Fonte: Elaborado pelos autores, com base no IBI. 


\section{ALESSANDRA CARVALHO DE VASCONCELOS, JOSÉ CARLOS LÁZARO DA SILVA-FILHO, \\ JOSÉ GLAUBER CAVALCANTE DOS SANTOS, ANNA BEATRIZ GRANGEIRO RIBEIRO MAIA}

Definida a amostra da pesquisa e sua distribuição nos grupos setoriais de inovação - Grupo 1: 14 empresas; Grupo 2: 32 empresas; Grupo 3: 20 empresas; Grupo 4: 34 empresas - realizou-se a transformação das variáveis referentes ao valor do intangível e valor de mercado por meio da função logarítmica, indicada por Martins e Theóphi- lo (2007), na aplicação de análise de regressão no estudo da relação funcional entre duas variáveis. O valor da taxa de Retorno do Patrimônio Líquido (ROE) não foi linearizado por representar um índice. A linearização obtida pela aplicação do modelo causou o efeito observado na diferença entre os gráficos de dispersão demonstrados na Figura 1.

Figura 1: Valor de mercado e intangíveis antes e depois da linearização

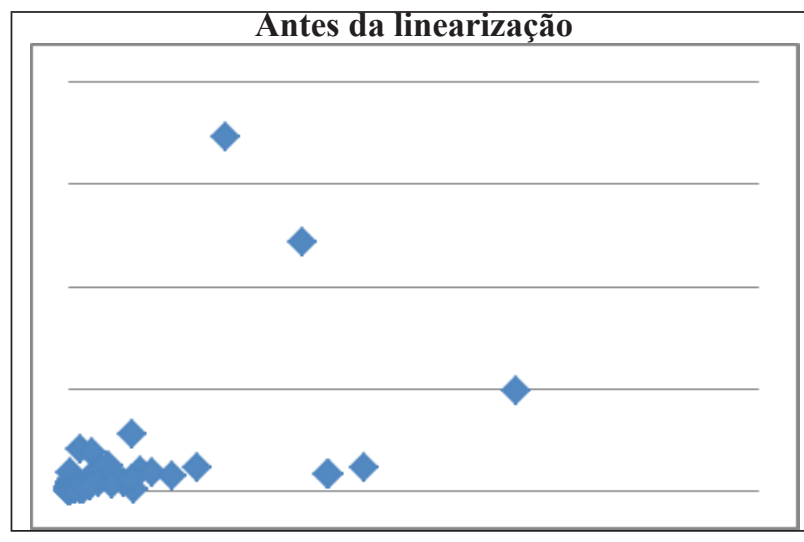

Fonte: Dados da pesquisa.

A pesquisa utiliza duas regressões lineares simples do tipo $y=a+b x$, para teste da $H_{1}$. Nesses tipos de equações, " $y$ " é a variável a ser explicada, representada pelo valor de mercado linearizado das empresas para a primeira sub-hipótese e o ROE para segunda. Em ambas as análises, 0 " $x$ " será representado pelo valor linearizado dos ativos intangíveis divulgados pelas empresas em suas Demonstrações Contábeis. Assim, será analisada a relação dos ativos intangíveis no valor de mercado e no retorno sobre o investimento dos acionistas das empresas.

Para teste da $\mathrm{H}_{2}$, também subdividida em duas sub-hipóteses, adicionou-se uma variável qualitativa (dummy) no intuito de investigar a influência do grupo setorial de inovação ao qual a empresa pertence no seu desempenho. Cada grupo foi analisado considerando inicialmente a sua relação com o valor de mercado e, posteriormente, com o ROE.

Estabelecidas as variáveis, passou-se ao processo de análise da regressão, utilizando aplicativo estatístico E-Views 5.0, com a finalidade de responder às hipóteses levantadas nesta pesquisa, considerando uma significância estatística de $5 \%(\square=0,05)$, considerado mais adequado nas pesquisas sociais, conforme destacado por Barbetta (2008, p. 186).

Por fim, cabe esclarecer que a estimação foi realizada por indivíduo (empresa) e por grupo setorial de inovação com o fim de investigar se a análise em grupo manteria consonância com a análise individual.

\section{ANÁLISE DOS RESULTADOS}

A análise dos resultados consistiu em investigar o efeito da variável independente (ativos intangíveis) no desempenho empresarial das empresas definidas na amostra da pesquisa. Nessa pesquisa considera-se desempenho empresarial como a geração de valor pelo mercado, analisado através do valor de mercado das empresas e pela taxa de retorno aos acionistas com base em dados contábeis por meio do indicador ROE.

A aplicação do teste de Hausman indicou a utilização das estimações por efeitos aleatórios, cujos resultados da regressão são evidenciados, inicialmente, considerando a relação entre os ativos intangíveis e as variáveis de desempenho das empresas e, em seguida, a relação entre o grau de inovação e o desempenho das empresas participantes dos setores mais inovadores do Brasil.

\section{Relação entre os ativos intangíveis e o desempenho empresarial}

Para o teste da hipótese $\left(H_{1}\right)$ foi aplicada a regressão linear simples, que consiste na relação entre a variável independente "Ativos intangíveis com evidenciação contábil" e o desempenho empresarial. Primeiramente analisado o "valor de mercado das empresas" e depois o "retorno sobre o patrimônio líquido (ROE)", cujos resultados são apresentados na Tabela 2. 
Tabela 2: Resultados dos modelos de regressão para análise de $\mathrm{H}_{1}$

\begin{tabular}{|c|c|c|c|c|}
\hline \multicolumn{5}{|c|}{ Influência dos ativos intangíveis no valor de mercado das empresas $-\mathrm{H}_{1}$} \\
\hline $\mathrm{R}^{2}:$ & \multicolumn{4}{|c|}{0,8666} \\
\hline Variáveis & Coeficiente & Erro Padrão & Z & $P>Z$ \\
\hline Intangíveis & 0,5488658 & 0,0377977 & 14,52 & 0,000 \\
\hline Constante & 8,233979 & 0,4219348 & 19,51 & 0,000 \\
\hline \multicolumn{5}{|c|}{ Influência dos ativos intangíveis no retorno sobre o patrimônio líquido (ROE) $-\mathrm{H}_{1.2}$} \\
\hline $\mathrm{R}^{2}:$ & \multicolumn{4}{|c|}{0,9779} \\
\hline Variáveis & Coeficiente & Erro Padrão & Z & \begin{tabular}{l|l|}
$P>$ & $Z$ \\
\end{tabular} \\
\hline Intangíveis & 0,0032807 & 0,0118750 & 0,28 & 0,782 \\
\hline Constante & 0,0905484 & 0,1298732 & 0,70 & 0,486 \\
\hline
\end{tabular}

Fonte: Dados da pesquisa.

As informações da Tabela 2 sugerem que os coeficientes se mostraram estatisticamente significantes

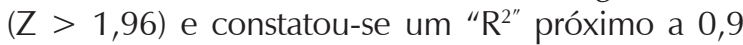
na relação entre os ativos intangíveis e o valor de mercado, indicando que os investimentos em intangíveis das empresas brasileiras de grupos setoriais intensivos em inovação explicam $86,66 \%$ dos seus valores de mercado. Por sua vez, os coeficientes resultantes da relação entre os ativos intangíveis e o retorno sobre o investimento dos acionistas (ROE) se mostraram estatisticamente insignificantes, não permitindo ponderações sobre seus valores.

A utilização do valor dos ativos intangíveis como fonte de informação por analistas de investimentos foi identificada por Antunes e Leite (2008) como sinalizador de resultados futuros para as empresas, interferindo positivamente no desempenho das organizações. Os dados da regressão correspondente a $\mathrm{H}_{1.1}$ revelam, por meio de seus coeficientes, que há uma relação de influência positiva entre os ativos intangíveis e o valor de mercado das empresas estudadas. Dessa forma, verifica-se que para cada $1 \%$ investido nesses ativos há um incremento de $54 \%$ no valor de mercado.

Damodaran (2007) indica a possibilidade de correlação entre a estrutura de capital das empresas e seu valor, indicando haver provas de que atividades propulsoras de alavancagem financeira aumentam o valor da empresa. Considerando essa abordagem, torna-se importante ressaltar uma restrição ao modelo proposto para validação de $\mathrm{H}_{1.1}$, pois o investimento em ativos intangíveis, por si só, aumentaria o valor de mercado ao influenciar na variação da estrutura de capital, seja pelo patrimônio líquido (capital próprio) ou por capitais de terceiros. Contudo, ao se analisar a relação entre os ativos intangíveis e o $\operatorname{ROE}\left(\mathrm{H}_{1.2}\right)$, constatou-se a insignificância estatística de seus coeficientes. Esse comportamento seria inesperado, pois o ROE possui o valor do patrimônio líquido em sua formulação (Lucro líquido / Patrimônio líquido), contribuindo para uma correla- ção forte nessa relação, que não foi constatada no estudo.

Em linhas gerais, os resultados estatísticos apresentados na Tabela 2 se alinham a pesquisas anteriores, como de Perez e Famá (2006) e de Lee e Chen (2009), que constataram, estatisticamente, que os ativos intangíveis são responsáveis pela maior geração de valor ao acionista, concluindo que altos níveis de investimento neste ativo intangível estariam associados a significantes crescimentos e geração de valor futuros. Nessa pesquisa constatou-se uma percepção desse investimento apenas quanto ao valor de mercado, propondo que investidores são suscetíveis a atribuir maior valor a empresas que realizem investimentos em ativos intangíveis.

Dessa maneira, os dados apresentados indicam a aceitação de $\mathrm{H}_{1.1}$ e rejeição de $\mathrm{H}_{1.2^{\prime}}$ apontando que os investimentos em intangíveis influenciam positivamente o valor de mercado das empresas participantes dos setores mais inovadores do Brasil.

\section{Relação entre o grau de inovação e o valor de mercado das empresas}

Para investigar a contribuição do grau de inovação das empresas, conforme grupos setoriais de inovação do IBI - Grupo 1: setores de alta tecnologia, Grupo 2: setores de média-alta intensidade tecnológica, Grupo 3: setores de média-baixa intensidade tecnológica e Grupo 4: setores de baixa intensidade tecnológica - para a maximização do valor de mercado das empresas, acrescentou-se uma variável (dummy) qualitativa de identificação de cada grupo setorial de inovação ao modelo de regressão inicial, figurando da seguinte forma:

$$
\gamma=\beta 0+\beta_{1} X_{1}+\beta_{1} X_{1} D_{1+\mu}
$$

Para o teste de $H_{2}$ : o grau de inovação das empresas de grupos setoriais inovativos relaciona- 
-se positivamente com o seu desempenho, aplicou-se a análise de regressão, ao mesmo nível de significância de 5\%. Primeiramente, considerando o valor de mercado como variável de desempenho empresarial e, posteriormente, com o retorno sobre o patrimônio líquido (ROE).

Com base nas premissas levantadas para a construção de $\mathrm{H}_{2}$ considerou-se, inicialmente, que as empresas classificadas em setores mais inovativos apresentariam maior intensidade no seu desempenho.

A Tabela 3 apresenta os resultados da aplicação do modelo de regressão nos grupos setoriais de inovação de 1 a 4.

Tabela 3: Estimações após aplicação de modelos com inclusão de dummies considerando o valor de mercado

\begin{tabular}{|c|c|c|c|c|}
\hline \multicolumn{5}{|c|}{ Influência dos ativos intangíveis no valor de mercado das empresas do Grupo 1} \\
\hline $\mathrm{R}^{2}:$ & \multicolumn{4}{|c|}{09600} \\
\hline Variáveis & Coeficiente & Erro Padrão & Z & $P>Z$ \\
\hline Intangíveis & 0,5533924 & 0,0377828 & 14,65 & 0,000 \\
\hline Grupo 1 & $-0,4257749$ & 0,3806077 & $-1,12$ & 0,263 \\
\hline Constante & 8,272787 & 0,4153107 & 19,92 & 0,000 \\
\hline \multicolumn{5}{|c|}{ Influência dos ativos intangíveis no valor de mercado das empresas do Grupo 2} \\
\hline$R^{2}:$ & \multicolumn{4}{|c|}{0,8630} \\
\hline Variáveis & Coeficiente & Erro Padrão & Z & \begin{tabular}{l|l}
$P$ & $Z$ \\
\end{tabular} \\
\hline Intangíveis & 0,5425018 & 0,0379931 & 14,28 & 0,000 \\
\hline Grupo 2 & 0,3653185 & 0,4945823 & 0,74 & 0,460 \\
\hline Constante & 8,166766 & 0,4601355 & 17,75 & 0,000 \\
\hline \multicolumn{5}{|c|}{ Influência dos ativos intangíveis no valor de mercado das empresas do Grupo 3} \\
\hline $\mathrm{R}^{2}:$ & \multicolumn{4}{|c|}{0,8662} \\
\hline Variáveis & Coeficiente & Erro Padrão & Z & \begin{tabular}{l|l}
$P>$ & $Z$ \\
\end{tabular} \\
\hline Intangíveis & 0,5408937 & 0,0380342 & 14,22 & 0,000 \\
\hline Grupo 3 & $-0,4828119$ & 0,5350222 & $-0,90$ & 0,367 \\
\hline Constante & 8,397984 & 0,4814829 & 17,44 & 0,000 \\
\hline \multirow{2}{*}{\multicolumn{5}{|c|}{ Influência dos ativos intangíveis no valor de mercado das empresas do Grupo 4}} \\
\hline $\mathrm{R}^{2}:$ & & & & \\
\hline Variáveis & Coeficiente & Erro Padrão & Z & \begin{tabular}{l|l}
$P>$ & $Z$ \\
\end{tabular} \\
\hline Intangíveis & 0,5497622 & 0,0377975 & 14,54 & 0,000 \\
\hline Grupo 4 & 0,3342797 & 0,3293 & 1,02 & 0,310 \\
\hline Constante & 8,123106 & 0,4333824 & 18,74 & 0,000 \\
\hline
\end{tabular}

Fonte: Dados da pesquisa.

As informações da Tabela 3 apontam para a impossibilidade de análise acerca da regressão aplicada, visto que todos apresentaram insignificância estatística $(Z<1,96)$.

Do exposto, os resultados dos modelos forneceram subsídios para rejeitar $\mathrm{H}_{2.11^{\prime}}$ visto que, com base na análise realizada na pesquisa, não se pode afirmar que existe uma relação significante estatisticamente entre o grau de inovação e o valor de mercado das empresas.
Na Tabela 4 são demonstrados os resultados das regressões decorrentes da relação entre os ativos intangíveis e o ROE de cada grupo de intensidade tecnológica do IBI (Grupo 1: alta tecnologia; Grupo 2: média-alta intensidade tecnológica; Grupo 3: média-baixa intensidade tecnológica; e Grupo 4: baixa intensidade tecnológica). 
Tabela 4: Estimações após aplicação de modelos com inclusão de dummies considerando o retorno sobre o patrimônio líquido (ROE)

\begin{tabular}{|c|c|c|c|c|}
\hline \multirow{2}{*}{\multicolumn{5}{|c|}{\begin{tabular}{l|l} 
& Influência dos ativos intangíveis no retorno sobre o patrimônio líquido das empresas do Grupo 1 \\
$R^{2}:$ & 0,9318
\end{tabular}}} \\
\hline & & & & \\
\hline Variáveis & Coeficiente & Erro Padrão & Z & \begin{tabular}{l|l|}
$P$ & $Z$ \\
\end{tabular} \\
\hline Intangíveis & 0,0032867 & 0,0119401 & 0,28 & 0,783 \\
\hline Grupo 1 & $-0,0022942$ & 0,1202800 & $-0,02$ & 0,985 \\
\hline Constante & 0,0908078 & 0,1312469 & 0,69 & 0,489 \\
\hline \multicolumn{5}{|c|}{ Influência dos ativos intangíveis no retorno sobre o patrimônio líquido das empresas do Grupo } \\
\hline $\mathrm{R}^{2}:$ & \multicolumn{4}{|c|}{0,4806} \\
\hline Variáveis & Coeficiente & Erro Padrão & Z & \begin{tabular}{l|l|}
$P$ & $Z$ \\
\end{tabular} \\
\hline Intangíveis & 0,0073797 & 0,0117433 & 0,63 & 0,530 \\
\hline Grupo 2 & $-0,2061107$ & 0,0879951 & $-2,34$ & 0,019 \\
\hline Constante & 0,1140252 & 0,1273937 & 0,90 & 0,371 \\
\hline \multicolumn{5}{|c|}{ Influência dos ativos intangíveis no retorno sobre o patrimônio líquido das empresas do Grupo } \\
\hline$R^{2}:$ & \\
\hline Variáveis & Coeficiente & Erro Padrão & Z & \begin{tabular}{l|l|}
$P>$ & $Z$ \\
\end{tabular} \\
\hline Intangíveis & 0,0089426 & 0,0117135 & 0,76 & 0,445 \\
\hline Grupo 3 & 0,2733716 & 0,1023581 & 2,67 & 0,008 \\
\hline Constante & $-0,0228004$ & 0,1329471 & $-0,17$ & 0,864 \\
\hline \multirow{2}{*}{\multicolumn{5}{|c|}{$\begin{array}{l}\text { Influência dos ativos intangíveis no retorno sobre o patrimônio líquido das empresas do Grupo } \\
\mathrm{R}^{2} \text {. }\end{array}$}} \\
\hline$R^{2}:$ & & & & \\
\hline Variáveis & Coeficiente & Erro Padrão & Z & \begin{tabular}{l|l|}
$P$ & $Z$ \\
\end{tabular} \\
\hline Intangíveis & 0,0032951 & 0,0119366 & 0,28 & 0,783 \\
\hline Grupo 4 & 0,0071252 & 0,0880776 & 0,09 & 0,926 \\
\hline & 0,0876362 & 0,1342983 & & \\
\hline
\end{tabular}

Fonte: Dados da pesquisa.

Os resultados dispostos na Tabela 4 sugerem não haver influência positiva entre todos os graus de inovação das empresas de grupos setoriais inovativos com o ROE, contudo, os grupos intermediários de inovação (2: média-alta intensidade tecnológica e 3: média-baixa intensidade tecnológica) apresentaram coeficientes significantes, possibilitando a sua análise.

No Grupo 2 o coeficiente apresentou-se negativo, sugerindo que para as empresas desse grupo o ROE é influenciado negativamente pelos investimentos em intangíveis. Esse contexto pode explicar-se pela natureza das atividades componentes do Grupo 2, quais sejam: fabricação de máquinas e equipamentos, fabricação de produtos químicos, refino de petróleo e álcool e telecomunicações. Nessas atividades o lucro líquido gerado pelos investimentos em intangíveis pode ocorrer no longo prazo dada a consolidação do produto ou serviço oferecido no mercado que impossibilita a sua diversificação. Assim, o patrimônio líquido aumentaria em virtude do aumento dos intangíveis e o lucro líquido não sofreria interferência no curto prazo, reduzindo o valor do ROE.

Entre as empresas componentes do Grupo 3, predominantemente voltadas aos setores têxtil, confecção, papel e celulose e couro, em que a diversificação de produtos exige resultados de curto prazo, a relação positiva pode ser explicada pela geração do lucro líquido no mesmo período da realização de investimentos em ativos intangíveis. Tratando-se de um indicador essencialmente contábil essa seria uma condição necessária para essa relação.

Esses resultados divergem dos achados de Santos, Basso e Kimura (2010), que identificaram diferenças entre a capacidade de inovar de uma empresa em relação ao setor econômico ao qual pertence, expondo, assim, relação positiva entre a inovação e o desempenho das firmas.

Com isso, atestou-se, nesta pesquisa, que o grau de intensidade em $P \& D$ não define o desempenho de mercado das empresas analisadas, fato que contraria o levantamento de Pavitt (1984) quanto à diferenciação de setores industriais, e de Lee e Chen (2009) quanto à sinalização que os investimentos em P\&D poderiam afetar o valor da empresa. Ainda assim, ressalta-se que a análise do retorno sobre o patrimônio líquido (ROE) indicou a influência de dois dos quatro grupos inovativos no seu valor, em que o Grupo 2 com influência negativa e o Grupo 3 com influência positiva. Observa-se, portanto, o caráter idiossincrático das empresas componentes de cada grupo setorial de inovação analisado.

\section{CONSIDERAÇÕES FINAIS}

O recente cenário de mudanças inerentes ao ambiente organizacional induz à questão de que 


\section{ALESSANDRA CARVALHO DE VASCONCELOS, JOSÉ CARLOS LÁZARO DA SILVA-FILHO, \\ JOSÉ GLAUBER CAVALCANTE DOS SANTOS, ANNA BEATRIZ GRANGEIRO RIBEIRO MAIA}

as empresas têm realizado mudanças em sua estrutura, com destaque para a absorção de recursos intangíveis, para gerar o máximo de benefícios advindos do processo inovativo.

Assim, conjecturou-se, inicialmente, que uma das principais motivações para o foco na inovação nas empresas parte do pressuposto de que aquelas com forte caráter inovador teriam intensivos investimentos em intangíveis e apresentariam vantagens competitivas capazes de influenciar a geração de valor para a empresa.

A pesquisa teve como objetivo principal analisar a relação entre as variáveis ativos intangíveis e grau de inovação e o desempenho das empresas listadas na BM\&FBovespa, participantes dos setores mais inovadores do Brasil, segundo classificação do Índice Brasil de Inovação (IBI).

Por meio da análise estatística da regressão, verificou-se o efeito da variável independente (ativos intangíveis) no desempenho das empresas e, complementarmente, examinou-se se a repercussão do grau de inovação da empresa - com base na classificação setorial de inovação do IBI - na maximização desse valor, buscando, assim, as hipóteses da pesquisa.

Em linhas gerais, os resultados obtidos forneceram subsídios para aceitar a hipótese de existência de relação entre os ativos intangíveis e o valor de mercado proposto na $\mathrm{H}_{1.1}$, indicando uma melhor percepção de investidores a esses recursos. Assim, ao se investir em recursos intangíveis o mercado reage no curto prazo aumentando o valor da empresa. Essa percepção não foi constatada na relação entre esses investimentos e o ROE, possivelmente pelo lapso temporal existente entre o investimento em ativos intangíveis e a geração do lucro contábil, refutando-se $\mathrm{H}_{1.2}$. Quanto à segunda hipótese proposta, há uma relação positiva entre grau de inovação das empresas e o desempenho empresarial, não foi possível analisar os coeficientes da sub-hipótese $\mathrm{H}_{2.1}$ diante da insignificância estatística dos coeficientes, portanto, nenhuma evidência pode ser inferida quanto a essa hipótese. Esse fato contraria a expectativa inicial de que uma maior intensidade tecnológica (indicador utilizado pelo IBI para a classificação das atividades econômicas das empresas nos quatro grupos setoriais de inovação) na empresa contribui para a maximização de seu valor de mercado. No entanto, leva a reflexões sobre a necessidade de inovar e investir em ativos intangíveis, mesmo em setores "não tão intensivos em inovação", pois a análise do ROE indica que empresas dos grupos intermediários de inovação (2: média-alta intensidade tecnológica e 3: média-baixa intensidade tecnológica), mas com exigência de diversificação em seus produtos e serviços são propulsoras de um melhor desempenho empresarial, explicado possivelmente pela ocorrência do lucro contábil no mesmo período da realização de investimento em ativos intangíveis.

Por fim, torna-se importante esclarecer que o estudo corrobora com pesquisas empíricas anteriores e que os resultados encontrados se restringem à realidade verificada na amostra e aos exercícios pesquisados.

Não à parte das demais pesquisas científicas, este estudo deparou-se com algumas limitações que impossibilitaram mais resultados, a se destacarem: (i) análise restrita aos exercícios de 2008 e 2009; (ii) a amostra intencional das empresas inovadoras classificadas nos grupos do IBI; e (iii) a utilização de duas proxies específicas - para os ativos intangíveis, os valores contábeis desses ativos evidenciados pelas empresas e para o grau de inovação, o grupo de intensidade tecnológica respectivo do IBI.

Diante do exposto, sugere-se que em trabalhos futuros sejam utilizadas outras técnicas estatísticas, como a análise discriminante, preferencialmente com séries temporais para melhor inferência entre as variáveis. Indicam-se, ainda, estudos comparativos que compreendam empresas que compõem atividades inovadoras e empresas de atividades não-inovadoras, diante da delimitação amostral desta pesquisa que abordou somente empresas inovadoras de setores de alta tecnologia, média-alta, média-baixa e baixa intensidade tecnológica, segundo o IBI.

\section{REFERÊNCIAS}

ALBUQUeRQUE JUNIOR, E. P.; LIMA, B. C. C.; LÁZARO, J. C. Inovação, estratégia e competitividade nas empresas brasileiras: uma investigação inicial sobre atividades inovativas e impactos, conforme o PINTEC 2008. RAUnP - Revista Eletrônica do Mestrado Profissional em Administração da Universidade Potiguar, v. 3, n. 2, p. 25-38, 2011.

ANTUNES, M. T. P.; LEITE, R. S. Divulgação das informaÇões sobre ativos intangíveis e sua utilidade para analistas de investimentos. Revista Universo Contábil, v. 4, n. 4, p. 22-38, out./dez. 2008.

ARANTES, E. C.; FURQUIM, N. R. Estratégias de internacionalização e de inovação como diferenciais para a expansão de uma empresa multinacional. InternexT Revista Eletrônica de Negócios Internacionais da ESPM, v. 6, n. 2, p. 116-137, 2011. 
ARCHIBUGI, D.; COCO, A. Measuring technological capabilities at the country level: a survey and a menu for choice. Research Policy, v. 34, p.175-194, 2005.

BARBETTA, P. A. Estatística aplicada às ciências sociais. 7. ed. Florianópolis: UFSC, 2008.

BARBOSA, A. C. Q.; CINTRA, L. P. Inovação, competências e desempenho organizacional - articulando construtos e sua operacionalidade. Future Studies Research Journal: Trends and Strategies, v. 4, n. 1, p. 31-60, 2012.

BARROS JUNIOR, L.; AGUIAR, J. F.; BASSO, L. F. C.; KIMURA, H. Intangible assets and value creation at Brazilian companies: an application for the Brazilian textile manufacturing sector. Journal of the Academy of Business and Economics, v. 10, p. 1-11, mar. 2010.

BLUNDELL, R.; GRIFFITHS, R.; VAN REENENL, J. Market share, market value and innovation in a panel of British manufacturing firms. Review of Economic Studies, v. 66, n. 3, p. 529-554, jul., 1999.

BRASIL. Lei no 11.638, de 28 de dezembro de 2007. Altera e revoga dispositivos da Lei no 6.404, de 15 de dezembro de 1976, e da Lei no 6.385, de 7 de dezembro de 1976, e estende às sociedades de grande porte disposições relativas à elaboração e divulgação de demonstrações financeiras. Disponível em: < http://www.planalto.gov.br/ ccivil_03/_ato2007-2010/2007/Lei/L11638.htm > . Acesso em: 06 nov. 2012.

Lei no 11.941, de 27 de maio de 2009. Altera a legislação tributária federal relativa ao parcelamento ordinário de débitos tributários; concede remissão nos casos em que especifica; institui regime tributário de transição, e dá outras providências. Disponível em: < http:// www.planalto.gov.br/ccivil_03/_Ato2007-2010/2009/Lei/ L11941.htm\#art37>. Acesso em: 27 nov. 2012.

BRASIL, M. V. O.; NOGUEIRA, C. A. G.; FORTE, S. H. A. C. Schumpeter e o desenvolvimento tecnológico: uma visão aplicada às pequenas e médias empresas (PMEs). Revista de Ciências da Administração, v. 13, n. 29, p. 38-62, 2011.

BRITO, E. P. Z.; BRITO, L. A. L.; MORGANTI, F. Inovação e o desempenho empresarial: lucro ou crescimento?. RAE Eletrônica, v. 8, n. 1, art. 6, jan./jun. 2009.

CARDOSO, V. I. C.; MAIA, A. B. G. R.; DE LUCA, M. M. M.; GALLON, A. V.; CUNHA, J. V. A. Intangible assets of innovative brazilian firms: a comparative analysis of firms with and without superior and sustained performance. In: AIB-LAT Conference, 2012, Miami. AIB-LAT Conference. Proceedings... Miami: FIU, 2012. v. 1. p. 1-38.
CARVALHO, M. M. Inovação: estratégias e comunidades de conhecimento. São Paulo: Atlas, 2009.

CPC - COMITÊ DE PRONUNCIAMENTOS CONTÁBEIS. Pronunciamento Técnico CPC 04 - Ativo Intangível, de 03 de outubro de 2008. Disponível em: < http://www. cpc.org.br/mostraOrientacao.php?id=27>. Acesso em: 07 dez. 2012.

Pronunciamento Técnico CPC 04 (R1) - Ativo intangível, de 05 de novembro de 2010. Disponível em: <http://www.cpc.org.br/pdf/CPC04_R1.pdf>. Acesso em: 30 nov. 2012.

CRISÓSTOMO, V. Ativos intangíveis: estudo comparativo dos critérios de reconhecimento, mensuração e evidenciação adotados no Brasil e em outros países. Contabilidade, Gestão e Governança, v. 12, n. 1, p. 50-68, jan./abr. 2009.

CVM - COMISSÃO DE VALORES MOBILIÁRIOS. Deliberação CVM no 644, de 02 de dezembro de 2010. Aprova o pronunciamento técnico CPC 04 (R1) do Comitê de Pronunciamentos Contábeis - CPC sobre ativo intangível. Disponível em: <http://www.cvm.gov.br/asp/cvmwww/ atos/Atos_Redir.asp?Tipo=D\&File=\%5Cdeli\%5Cdeli644. doc $>$. Acesso em: 30 nov. 2012.

DAFT, R. L. A dual-core model of organizational innovation. Academy of Management Journal, v. 21, p. 193-210, 1978.

DAMANPOUR, F. The adoption of technological, administrative, and ancillary innovations: impact of organizational factors. Journal of Management, v. 13, n. 4, p. 675-688, 1987.

; WALKER, R. M.; AVELLANEDA. C. N. Combinative effects of innovation types and organizational performance: a longitudinal study of service organizations. Journal of Management Studies, v. 46, n. 4, p. 650-675, jun. 2009.

DAMODARAN, A. Avaliação de empresas. 2. ed. São Paulo: Pearson Prentice Hall, 2007.

DARROCH, J.; McNAUGHTON, R. Examining the link between knowledge management practices and types of innovation. Journal of Intellectual Capital, v. 3, n. 3, p. 210-222, 2002.

DOSI, G. Mudança técnica e transformação industrial. Série Clássico da Inovação. Campinas: Editora Unicamp, 2006.

DURAND, D Cost of debt and equity funds for business: trends and problems of measurement. In: CONFERENCE 
ON RESEARCH ON BUSINESS FINANCE, 1952, New York. Proceedings... New York: [s.n.], 1952.

EDVINSSON, L.; DVIR, R.; ROTH, N.; PASHER, E. Innovations: the new unit of analysis in the knowledge era: The quest and context for innovation efficiency and management of IC. Journal of Intellectual Capital, v. 5, n. 1, p. 40-58, 2004.

EUROPEAN COMISSION. European innovation scoreboard 2006: comparative analysis of innovation performance. União Europeia: Pro Inno Europe, 2006. Disponível em: <http://www.proinno-europe.eu/doc/EIS2006_final. pdf $>$. Acesso em: 09 dez. 2012.

FURTADO, A.; QUADROS, R. Construindo o IBI. Revista Inovação UNIEMP, v. 2, n. 3, p. 26-27, jul./ago. 2006.

; RIGHETTI, S.; INÁCIO JR., E.; DOMINGUES, S.; CAMILLO, E. Índice Brasil de Inovação: manual informativo sobre o procedimento de adesão das empresas. Campinas: UNICAMP/IG/DPCT e LABJOR, 2007.

; DOMINGUES, S. A. Intensidade de P\&D das empresas brasileiras. Revista Inovação UNIEMP, v. 3, n. 6, p. 26-27, nov./dez. 2007.

GARCIA, R.; CALANTONE, R. A critical look at technological innovation typology and innovativeness terminology: a literature review. Journal of Product Innovation Management, v. 19, p. 110-132, 2002.

GARCÍA-MORALES, V. J.; JIMÉNEZ-BARRIONUEVO, M. M.; GUTIÉRREZ-GUTIÉRREZ, L. Transformational leadership influence on organizational performance through organizational learning and innovation. Journal of Business Research, v. 65, n. 7, p. 1040-1050, jul., 2012.

IBGE - INSTITUTO BRASILEIRO DE GEOGRAFIA E ESTATÍSTICA. Pesquisa de inovação tecnológica - PINTEC 2005: instruções para preenchimento do questionário. Rio de Janeiro: IBGE, 2006.

Pesquisa de inovação tecnológica 2008. Rio de Janeiro: IBGE, 2010. Disponível em: <http://www.ibge. gov.br/>. Acesso em: 15 nov. 2012.

INÁCIO JÚNIOR, E.; QUADROS, R. Apresentando a fórmula do IBI. Revista Inovação UNIEMP, v. 2, n. 5, p. 26-27, nov./dez. 2006.

JEFFERSON, G.; HU, A. G.Z.; XIAOJING, G.; XIAOYUN, $Y$. Ownership, performance, and innovation in China's large-and-medium-size industrial enterprise sector. China Economic Review, v. 14, n. 1, p. 89-113, 2003.
JENSEN, M. C.; MECKLING, W. H. Theory of the firm: managerial behavior, agency costs and ownership structure. Journal of Financial Economics, v. 3, n. 4, p. 305360, oct. 1976 .

KAPLAN, R. S.; NORTON, D. P. Organização orientada para a estratégia: como as empresas que adotam o balanced scorecard prosperam no novo ambiente de negócios. Rio de Janeiro: Campus, 2000.

KIMBERLY, J. R.; EVARISKO, M. J. Organizational innovation: the influence of contextual factors on hospital adoption of technological and administrative innovations. Academy of Management Journal, v. 24, p. 689-713, 1981.

KIRNER, E.; KINKEL, S.; JAEGER, A. Innovation paths and the innovation performance of low-technology firms: an empirical analysis of German industry. Research Policy, v. 38, n. 3, p. 447-458, apr. 2009.

KOELLINGERA, P. The relationship between technology, innovation, and firm performance: empirical evidence from e-business in Europe. Research Policy, v. 37, n. 8, p. 1317-1328, sep., 2008.

KUSTHER, E. A.; BINOTTO, E.; SIQUEIRA, E. S.; NOGUEIRA, M. A. F. S.; CASAROTTO, E. L. Inovação tecnológica e suas influências no processo de gestão: uma análise no setor de segurança privada patrimonial. Revista Gestão Organizacional, v. 3, n. 1, p. 7-26, jan./jun. 2010.

LEV, B. Intangibles: management, measurement and reporting. Washington: Brookings Institution Press, 2001.

LEE, R. P.; CHEN, Q. M. The immediate impact of new product introductions on stock price: the role of firm resources and size. Journal of Product Innovation Management, v. 26, n. 1, p. 97-107, 2009.

LICHTENTHALER, U. Outbound open innovation and its effect on firm performance: examining environmental influences. R\&D Management, Special Issue: Open R\&D and Open Innovation, v. 39, n. 4, p. 317-330, Sep. 2009.

MARTINS, G. A.; THEÓPHILO, C. R. Metodologia da investigação científica para ciências sociais aplicadas. São Paulo: Atlas, 2007.

MUDAMBI, R. Location, control and innovation in knowledge-intensive industries. Journal of Economic Geography, n. 8, p. 699-725, 2008.

NARVEKAR, R. S.; KARUNA, J. A new framework to understand the technological innovation process. Journal of Intellectual Capital, v. 7, n. 2, p. 174-186, 2006. 
NISIYAMA, E. K.; OYADOMARI, J. C. T. A busca da inovação e a cadeia de valores. Revista de Administração da Unimep, v. 10, n. 1, p. 189-214, 2012.

OECD - ORGANISATION FOR ECONOMIC CO-OPERATION AND DEVELOPMENT. Oslo manual: proposed guidelines for collecting and interpreting technological innovation data. Paris: OCDE, 2005.

OYADOMARI, J. C. T.; CARDOSO, R. L.; SILVA, B. O. T.; PEREZ, G. Sistemas de controle gerencial: estudo de caso comparativo em empresas inovadoras no Brasil. Revista Universo Contábil, v. 6, n. 4, p. 21-34, out./dez. 2010.

PAVITT, K. Sectoral patterns of technical change: towards a taxonomy and a theory. Research Policy, n. 13, p. 343-73, 1984.

PEREZ, M. M.; FAMÁ, R. Características estratégicas dos ativos intangíveis e o desempenho econômico da empresa. Revista Eletrônica de Gestão de Negócios, v. 2, n. 2, p. 69-96, abr./jun. 2006.

QUADROS, R.; FURTADO, A. Índice Brasil de Inovação: a próxima etapa. Revista Inovação UNIEMP, v. 3, n. 5, p. 26-27, set./out. 2007.

QUEIROZ, O. R. O impacto do crescimento dos gastos em P\&D na taxa de crescimento dos lucros das empresas de acordo com Modelo OJ: um estudo no mercado de capitais brasileiro. In: CONGRESSO ANPCONT, 4, 2010, Natal. Anais... São Paulo: ANPCONT, 2010.

RIGHETTI, S.; PALLONE, S. Consolidando também o conceito de inovação tecnológica. Revista Inovação UNIEMP, v. 3, n. 4, p.26-27, jul./ago. 2007.

RITTA, C. O.; ENSSLIN, S. R. Investigação sobre a relação entre ativos intangíveis e variáveis financeiras: um estudo nas empresas brasileiras pertencentes ao índice Ibovespa nos anos de 2007 e 2008. In: CONGRESSO USP DE CONTABILIDADE E CONTROLADORIA, 10, 2010, São Paulo. Anais... São Paulo: USP, 2010.

ROGERS, M. The definition and measurement of innovation. Melbourne Institute Working Paper, n. 10, may, 1998.

ROSENBUSCHA, N.; BRINCKMANNB, J.; BAUSCH, A. Is innovation always beneficial? A meta-analysis of the relationship between innovation and performance in SMEs. Journal of Business Venturing, v. 26, n. 4, p. 441-457, jul, 2011.

SANTOS, D. F. L.; BASSO, L. C.; KIMURA, H. The influence of innovation on firm performance in Brazil. Feb., 2010, 44p. Disponível em: < http://ssrn.com/abstract $=1555067>$. Acesso em: 08 nov. 2012.
SANTOS, J. G. C.; SILVA, L. S.; GALLON, A. V.; DE LUCA, M. M. M. Intangibilidade e inovação em empresas no Brasil. Revista de Administração e Inovação, v. 9, p. 197-221, 2012.

SCHUMPETER, J. A. A teoria do desenvolvimento econômico. 3. ed. Coleção Os Economistas. São Paulo: Nova Cultural, 1988.

SORESCU, A.; SPANJOL, J. Innovation's effect on firm value and risk: insights from consumer packaged goods. Journal of Marketing, v. 72, p. 114-132, mar. 2008.

SPENCE, M. Job market signaling. Quarterly Journal of Economics, v. 87, 355-374, 1973.

SQUENA, R.; PASUCH, D. F. Goodwill: sua definição e relevância para a área contábil. Revista Gestão Organizacional, v. 3, n. 1, p. 44-57, jan./jun. 2010

STOECKICHT, I. P.; SOARES, C. A. P. A importância da gestão do capital social para o desenvolvimento da capacidade de inovar em empresas brasileiras. INGEPRO - Inovação, Gestão e Produção, v. 2, n. 10, p. 23-37, out. 2010.

TEH, C. C.; KAYO, E. K.; KIMURA, H. Marcas, patentes e criação de valor. Revista de Administração Mackenzie, v. 9, n. 1, p. 86-106, 2008.

TIRONI, L. F.; CRUZ, B. O. Inovação incremental ou radical: há motivos para diferenciar? Uma abordagem com dados da PINTEC. Texto para Discussão n 1360. Rio de Janeiro: Instituto de Pesquisa Econômica Aplicada - IPEA, out. 2008.

ZALTMAN, G.; DUNCAN, R.; HOLBEK, J. Innovations and organizations. New York: Wiley, 1973. 